\title{
Development of Water-Surface Robotic Vehicle to Assist Communication Between Remotely Operated Vehicle Underwater Robot and Control Station
}

\author{
Ronny Mardiyanto, Badrut Tamam \\ Dept. of Electrical Engineering \\ Sepuluh Nopember Institute of Technology \\ Surabaya, Indonesia \\ ronny@elect-eng.its.ac.id, tamambadrut13@gmail.com
}

\begin{abstract}
This paper developed a water-surface robotic vehicle that act as repeater station to assist the communication between ROV (Remotely Operated Vehicle) underwater robot and control station. The key issue here is how the robot can relay the data communication between the ROV and the control station. The communication between repeater Station and control station is based on wireless, whereas the communication between repeater Station and ROV is based on wire. Data that have transmit from control station is received by Repeater Station and continued to the ROV through wire. The Power needed is suplied by photovoltaic (PV) to the Repeater Station and the ROV. The position of Repeater Station is controlled, so the position of Repeater Station and ROV always in parallel. In practices, there are two way directly communication between control station with ROV, that are based on wireless and through wire. Nevertheless, wireless communication system never used to observed on the ocean or the deep waters because there is a high attenuation of a signal when cross the air-water boundary. Based on these problems, we make a Repeater Station that used a buoyant communication system models. Communication from control station to Repeater Station in the form of motion control and data. Whereas, communication from Repeater Station to ROV in the form of motion control, data, and power supply. Communication frequency is at 5,8 GHz for audio video and $433 \mathrm{MHz}$ for motion control and telemetry. The connection wire between Repeater Station and ROV can go along and shorten with automatically roll as feature. Electricity from PV is strorage to a battery in the Repeater Station. Charging of the battery occur when battery power is not full and will cease if battery power is being full. Power of the battery must be full if want to operated the Repeater Station. The availability of the Repeater Station is expected to assist the communication between ROV underwater robot with control station, so ROV can be controlled remotely and can increase range of the reach.
\end{abstract}

Keywords-Water-Surface Robotic Vehicle; Communication; Position Control; Repeater Station; Self Charging

\section{INTRODUCTION}

Indonesian waters area that avowed by United Nation Convention of the Sea (UNCLOS) attain $2 / 3$ of the area of Indonesia. That area has much of "gold" so research activity of the geological and geophysical directed to the ocean. Before the ROV (Remotely Operated Vehicle) are presence, undersea observation doing by the divers. Then, ROV has developed to minimalize the limitation of human like the human cannot held high pressure, extreme temperature, and others [1].

ROV, mini dive vehicle, is to assist human in ocean exploration especially for place that cannot people reach like object inside a little cave with 3000 metres in deep [2]. For the example is on the case of AirAsia Qz8501 accident, ROV successed to found the black box in undersea. Fig. 1 shown the ROV that used to found a AirAsia black box [3].

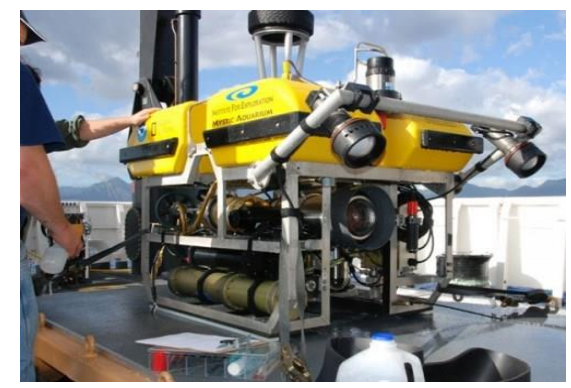

Fig. 1. ROV That Used to Found AirAsia QZ8501 Black Box [3]

ROV technology is became the workhorse in oil and gas exploration for decades and have important job on marine renewable energy (MRE) and marine civil engineering industries for military utility, ocean observation utility, and others. The purpose of ROV in specific is used to inspection, repair, and maintenance sub-sea gas pipes. Be sides, there are much of ROV useful applications for our life [4].

Commonly, ROV is tether with the pilot in the island or on top of a ship using an umbilical cable [5]. ROV system is on top of the ship. The ship is equipped with DGPS (Differential Global Positioning System) as determining prime position. Whereas, for determining position of ROV in underwater use an Acoustic Underwater Positioning [6]. The pilot is stay while ROV have trace the object in underwater, so the movement of ROV depend on the length of cable. This problem cause ROV movement is limitation [3].

In practices, there are two way directly communication between control station with ROV, that are based on wireless and through a cable. Nevertheless, wireless communication system never used to observed on the ocean or the deep waters because there is a high attenuation of a signal when cross the air-water boundary that cause by reflection or refraction [5].

Based on the problems above, we have design and development of Repeater Station to assist the communication between ROV underwater with control station. This Repeater Station can move follow the direction of the ROV and the position will parallel with ROV. The Repeater Station with ROV is tether using an umbilical cable, whereas the Repeater Station with control station is connecting in wireless way. The tethered cable of Repeater Station with ROV has automatic roll as feature or it can go along and shorten appropriate ROV needed to dive the ocean. Equipped with GPS to determining the position of Repeater Station and acoustic underwater positioning to determine 
the position of ROV on undersea, and accompanying position control system such that position of Repeater Station can be parallel with the ROV. Not only that, Repeater Station used a PV to occupy the power of Repeater Station and the ROV. The availability of the Repeater Station is expected to assist the communication between ROV underwater robot with control station, so ROV can be controlled remotely and can increase range of the reach. The goals of this design is we will make the ROV can resistance to any weather, to assist the communication between ROV with control station, regulate the electricity system to charge the battery which have supplied from PV, and regulate the position control of Repeater Station.

\section{RELATED WORKS}

\section{A. Underwater Robot}

Underwater robot is one of a kind unmanned robot which applications for ocean observation activity. There are two kind of underwater robot, that is Autonomous Vehicles (AUVs) and Remotely Operated Vehicles (ROVs). AUVs can operates according to the commands on chip which used by AUVs robot. Whereas, ROVs can operated under control of the pilot. Generally, AUVs and ROVs always be equipped with cameras, lamp, sensors, and others appropriate to the purpose of observation [6].

\section{B. Remotely Operated Vehicle (ROV)}

ROV can operated under control of the pilot that connected through an umbilical cable. Through this umbilical cable, electricity, data, and signal transmit bidirectional to the ROV operator, so the operator can analyze it. ROV usability involve sector of military, industries, observation, and other sectors. In military sector, American navy is first for used ROV in 1960, that is they used ROV to derive mines in sea floor and they used when an atom bomb is missed on a plane accident in Spain. In Industry sector, oil and gas industries used ROV to do exploration and that was become a trend for decades [4].

In general, camera and lamp is the most additional feature. But, to support the capability of ROV, ROV is equipped by other sensors depend on the objective of making ROV. Tools or sensors that used as usual is camera, lamp, transponder, compass, odometer, bathy, sonar, magnetometer, temperature sensor, etc. [3].

There are five kinds of ROV based on dimension, weight, and strength, that is micro ROV, mini ROV, light work class, heavy work class, and trenching/burial. Micro ROV and mini ROV is used for less than 300 meter deeps. Work class type is used for offshore drilling, survey and undersea gas pipe rectification. Sample of work class type is Venom that shown in fig. 2. Venom can operate until 3000 meter deeps and controlled by hydraulic power [6].

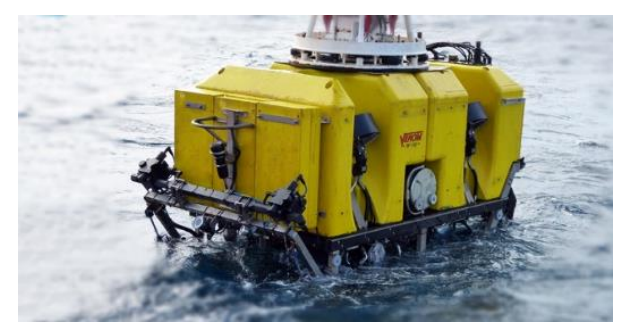

Fig. 2. Venom 3k-200 Work class ROV [7]

\section{Radio Control $(\mathrm{RC})$}

Radio control (RC) is a control device that uses radio waves. Its use to control a vehicle's in wireless way. The applications are on more sectors, like industries, military, observation, and others. The system on RC is uses open loop system, which transmitter send a control data and received by receiver without any feedback. Data is send through a radio waves frequency so receiver will modify it become discrete signal. Frequency at 2,4 $\mathrm{GHz}$ and $72 \mathrm{MHz}$ are in usually used. Fig. 3 shown the RC equipment [8].

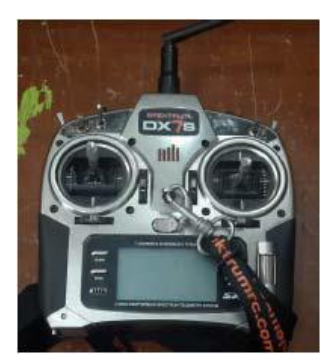

(a)

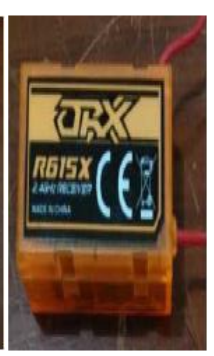

(b)
Fig. 3. RC Equipment (a) DX7s RC Transmitter (b) Orange Rx Receiver [8]

\section{Underwater Communication}

Underwater communication can use sonar waves or electromagnetic waves. Sonar communication system divided to two, that is passive sonar and active sonar. Passive sonar communication derived a sonar waves that transmit in underwater. Active sonar communication can receive sonar waves as well as transmit. Both of it used hydrophones as transmitter and receiver a wave. Communication system with sonar cannot used on communication system that through air-water boundary, because there is high attenuation at the amplitude of that sonar waves.

Electromagnetic communication system is an alternative to communication that through air-water boundary. This system used an antenna to transmit and receive electromagnetic waves. There are two architectures in this system, buoyant and direct underwater communication system. Buoyant system used only one antenna in air, whereas direct system used two antennas in air and underwater. Fig. 4 and fig. 5 shown the buoyant and direct underwater communication system [9].

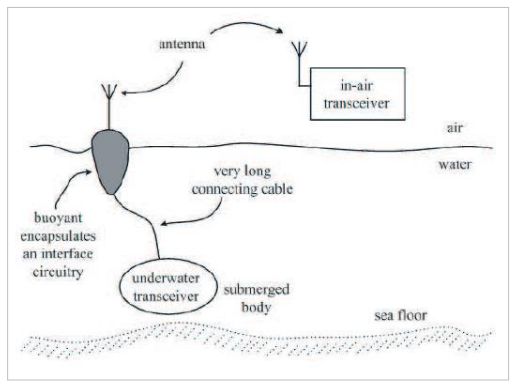

Fig. 4. Buoyant Communication System

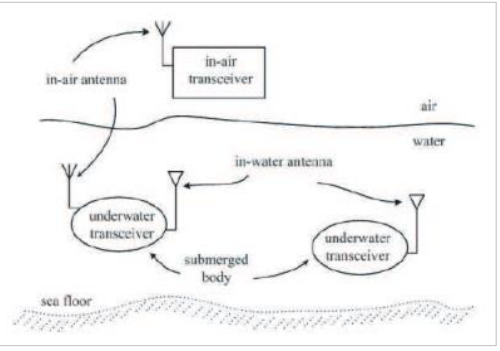

Fig. 5. Direct Communication System

\section{E. Acoustic Underwater Positioning}

GPS cannot use to determine object position in underwater because there is an attenuation of the waves. One alternative is underwater acoustic positioning systems. Hydro-acoustic positioning is based on triangulation basic principle and working by measuring the time of flight. When the time is measured, the 
position can determine. There are two methods to determine underwater object position, namely Ultra Short Base Line (USBL) and Long Base Line (LBL) systems.

USBL system used two equipment to determine ROV position, interrogator and transponder. Interrogator is a combination between transmitter and receiver which send acoustic signal on one frequency and receive the respond on other frequency. This device is on a ship, whereas transponder is mounted on underwater robot. Transponder send respond signal when have received signal from interrogator. Distance from robot and interrogator measured by measuring time of flight in water. Angle tilt of a respond signal measure by used phase shift between some hydrophones in the interrogator element. The combination between distance and angle tilt enable to know the position of ROV. USBL system shown in fig. 6.

LBS system contain one or some interrogator, and a set of others transponder, called pingers. Pingers is a device which send an acoustic signal as sustainably with specific frequency. In this system, interrogator is mounted in ROV, and interrogator utilize others beacon acoustic respond to measure distance from each device. The beacon is mounted on the sea floor which known the position. Robot and interrogator use trilateration to determine the position relatively to the beacons. LBL system shown in fig. 7 [10].
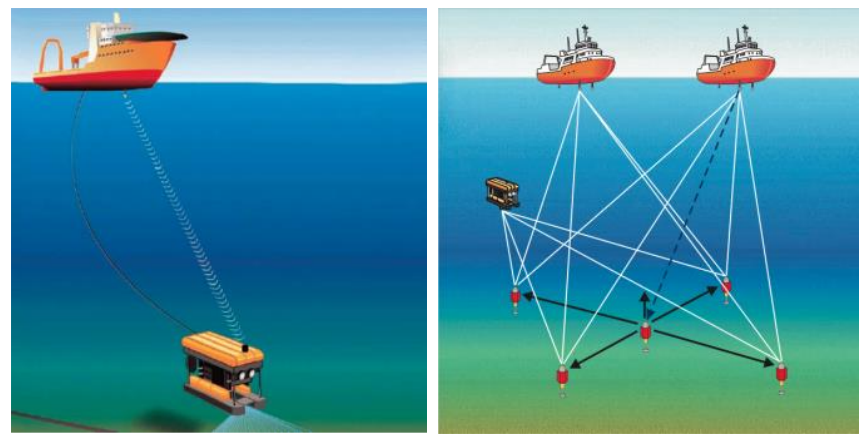

Fig 6. USBL System Scheme

Fig. 7. LBL System Scheme

\section{F. Photovoltaic $(P V)$}

Photovoltaic (PV) is a semiconductor material which can convert the light become electric directly. It can do it because photoelectric effect that absorb photon and release electrons. Total power from PV proportional with operation voltage multiplied with operation current. The utilize of PV with battery always used charge controller system. So that used of battery and electric energy will optimum and safely. Charge controller can regulate minimum and maximum voltage from battery so system will be safely. When overcharging from PV, overused by the load, prohibit current back to the PV, and can prohibit short circuit on the load. Fig. 8 show Basic concept of charge controller [11].

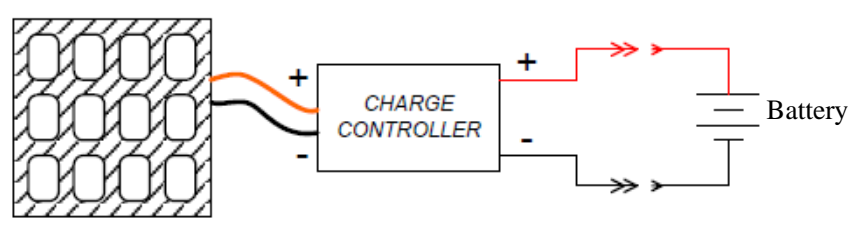

Photovoltaic

Fig. 8. Basic Concept of Charge Controller

\section{PROPOSED METHOD}

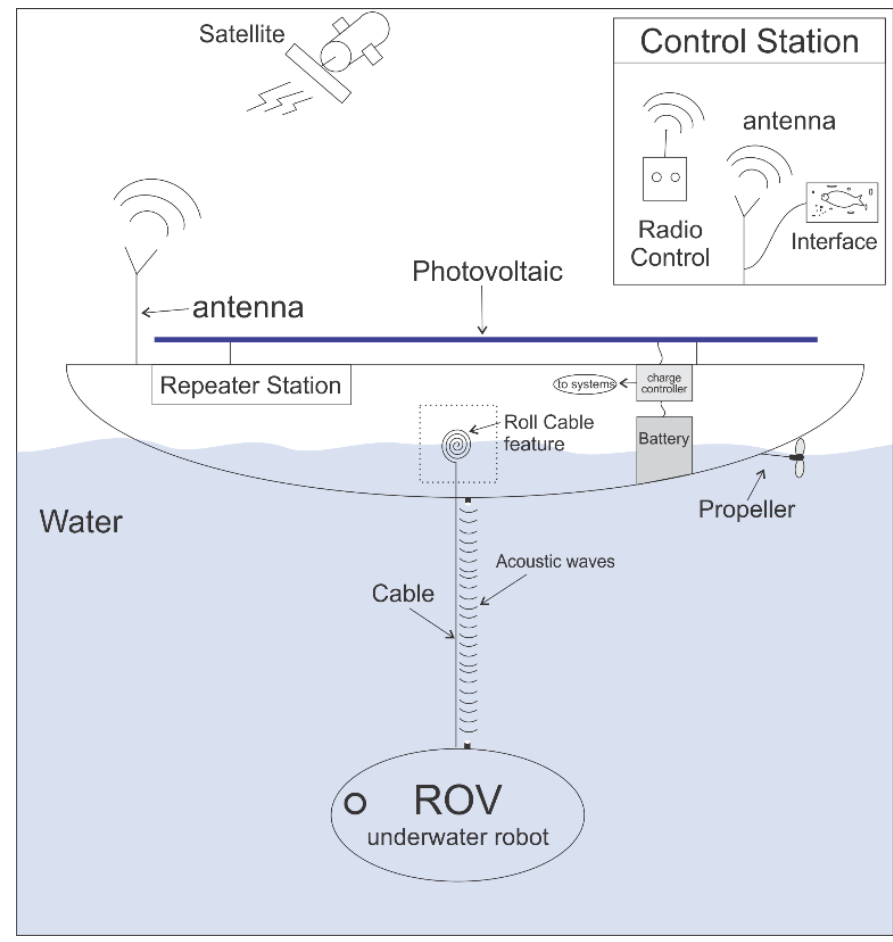

Fig. 9. Repeater Station Design Concepts

Fig. 9 shown design concept of the Repeater Station. At fig. 9 , there are three basic systems, that is communication system, charging system, and control position system.

The main objective of the Repeater Station is to assist the communication between ROV underwater robot with control station. The Repeater Station is a bridge wireless communication for ROV and control station, so ROV can control by wireless although it not directly. Communication between control station with Repeater Station are by wireless, but the communication between Repeater Station with ROV are through umbilical cable. In principle, signal from control station is propagated to the Repeater Station and it will be propagated to the ROV. Those is a bidirectional communication.

Wireless communication from control station to the Repeater Station or conversely used frequency channel at $5,8 \mathrm{GHz}$ for video transmission and $433 \mathrm{MHz}$ for control and data transmission. Control transmit from control station to the Repeater Station. Whereas, video and data transmit from Repeater Station to the control station. The position of Repeater Station can determine by using GPS tracker. Location, observation result, and observation video will be displayed to the monitor.

The position of the Repeater Station on surface is lock with the ROV, so the position between Repeater Station and ROV will parallel. Because Repeater Station is in controlled with control system, so the Repeater Station will adjust the position by self. Position control system is working by determine ROV position with acoustic underwater positioning. ROV position is known, so the Repeater Station will move automatically so that position will be parallel with ROV.

Automatic roll system at connected cable for Repeater Station with ROV is control with system control too. That cable can go along and shorten as ROV needed to go dives. For example, when ROV will go to dive 5 meter in deeps, so that the cable will go along until 5 meter longs. The movement between the roll is proportional with ROV vertical movement.

All systems, control system and the others system which have mounted on the Repeater Station is used power from PV. 
PV power is stored in the battery and the charging condition is regulated with the charge controller. Charging logic is when battery is not full or empty, PV will charge the battery and will be stop when the battery power is full. Power used for all system is regulated by charge controller too, if battery power still not full, the system will be supplied by battery which at the same time the battery is being filled. Whereas, when battery power is full, charging for battery will stopped by charge controller and redirected for used to the system directly through the charge controller.

\section{EXPERIMENTAL RESULT}

In order to measure the performance of the proposed system, we have realized it as shown in fig. 10 .

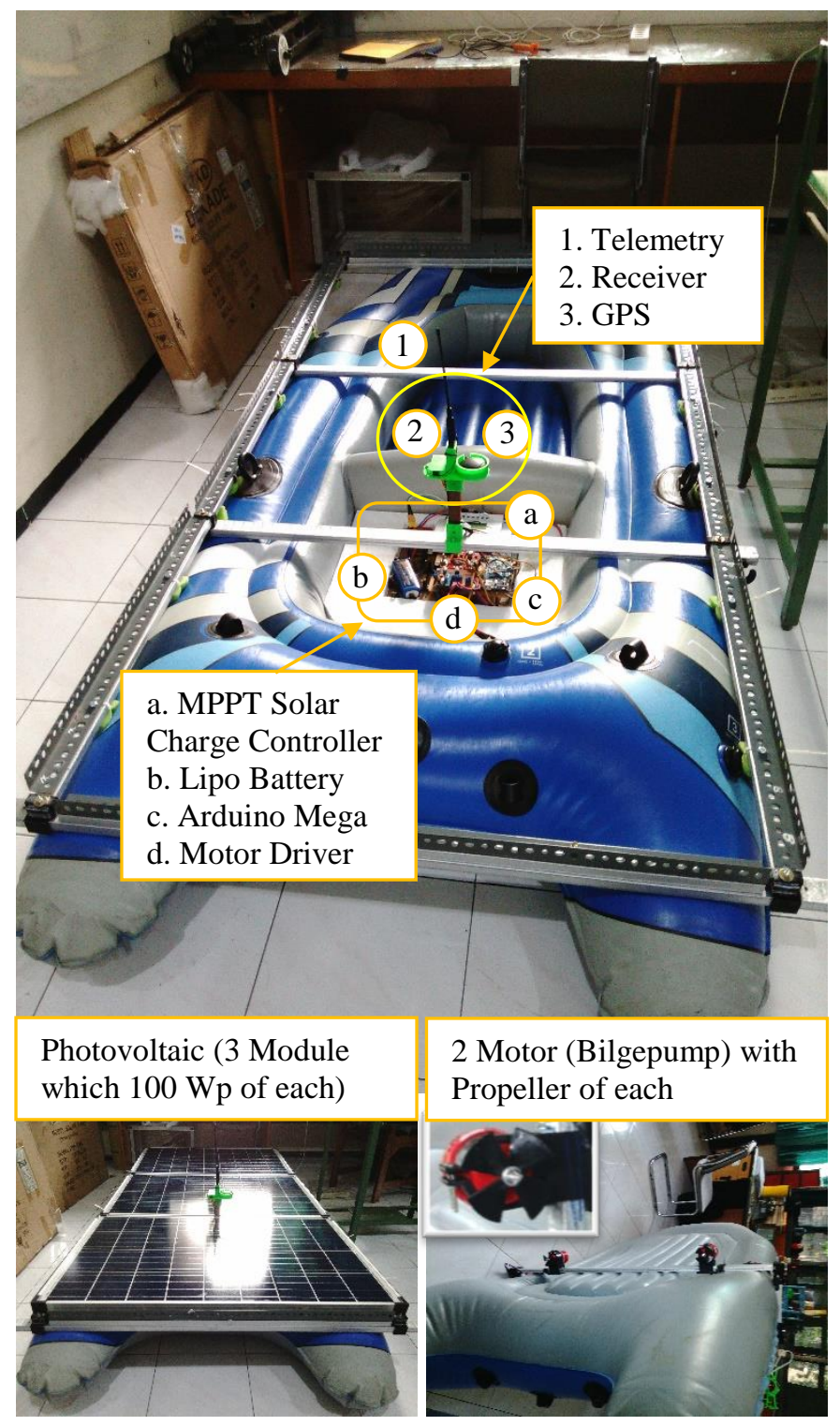

Fig. 10. Realization of Repeater Station

This Repeater Station consists of rubber boat, controller (this robot used an Arduino Mega 2560), motor driver, motor with propeller, telemetry, receiver, GPS, PV Module, and MPPT solar charge controller.

To assist the communication between ROV and ground station, this repeater station is fully equipped with 3 modes control, that are manual control, autopilot mode, and loiter mode. The three modes has tried in Lake 8 Sepuluh Nopember Institute of Technology (Danau 8 ITS) that shown in fig. 11.

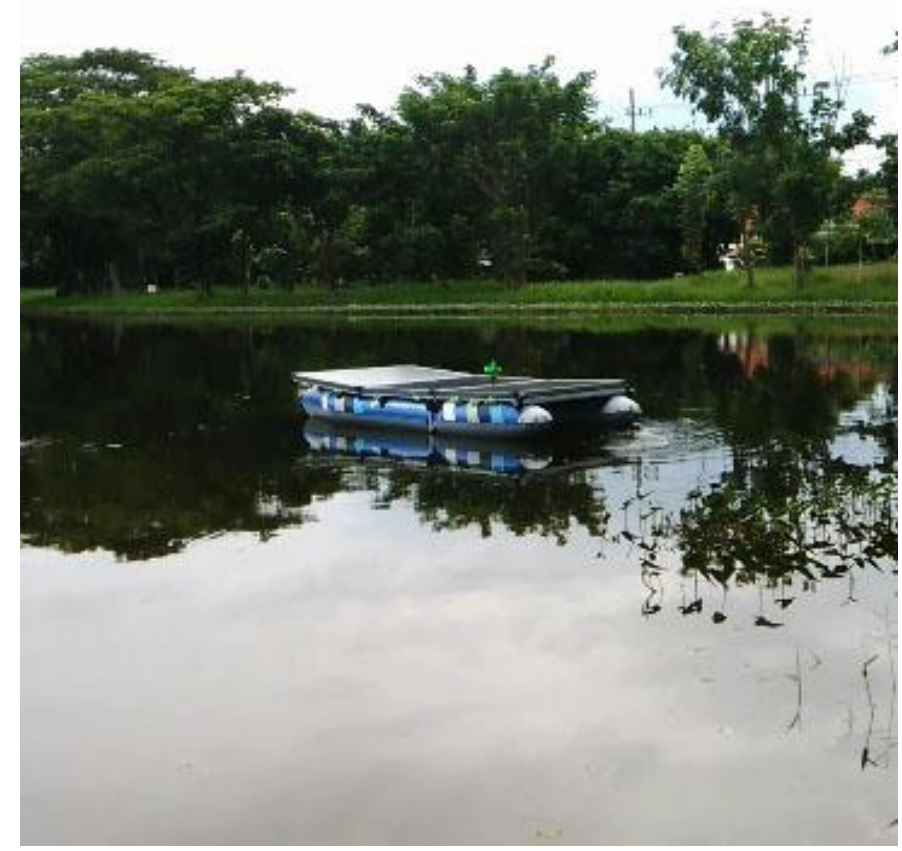

Fig. 11. Testing Three Modes Control at Lake 8 ITS

The explanation of that control modes are: (a) Manual control mode is used to control the movement of the Repeater Station using a Remote Control, in this project i use Radiolink AT9. In manual mode, we can control the repeater station to go forward, go back, turn left, turn right, and idle appropriate on command from user. (b) Autopilot mode is a feature to lock location. So, the Repeater Station can move from a coordinate to others coordinate that have set in arduino code program before. In this experiment three coordinate has used, (1) 7.286343, 112.795952; (2) -7.286410, 112.796014; (3) $7.286299,112.796076$. The movement is control by using PID controller, and use gain value of $\mathrm{kp}=0.055, \mathrm{ki}=0$, and $\mathrm{kd}=$ 0.025 . (c) Loiter mode is made to lock location. So, if the Repeater Station has move as far as 2 meters from lock location, the Repeater Station will move and back to the lock location. The purpose of this loiter mode is to hold the position of the Repeater Station while the ROV going to dive and observed underwater. Same with autopilot mode, loiter mode is use PID too to control the movement of the Repeater Station.

In addition, data communication from Repeater Station is transmit using a pair of telemtry in channel $433 \mathrm{MHz}$. To collect data, arduino ide has connect with MS. Excel using PLX-DAQv2.10. Graphical user of this PLX-DAQ-v2.10 is shown in fig. 12.

\begin{tabular}{|c|c|c|c|c|c|c|}
\hline$\Delta$ & A & \multicolumn{2}{|r|}{$B$} & C & D & $E$ \\
\hline 24 & $12 / 03 / 2017$ & \multicolumn{2}{|c|}{ 1.10.28 PM } & 2.484375 & 22 & 829 \\
\hline 25 & $12 / 03 / 2017$ & 1.1 & $0.28 \mathrm{PM}$ & 2.511719 & 23 & 859 \\
\hline 26 & $12 / 03 / 2017$ & \multirow{2}{*}{\multicolumn{5}{|c|}{ 1. PLX-DAQ for Excel "Version 2" by Net^ ${ }^{\wedge}$ Devil }} \\
\hline 27 & $12 / 03 / 2017$ & & & & & \\
\hline 28 & $12 / 03 / 2017$ & 1. & \multirow{4}{*}{\multicolumn{2}{|c|}{$\begin{array}{l}\text { PLX-DAQ } \\
\text { Settings }\end{array}$}} & Control & v. 2.10 \\
\hline 29 & $12 / 03 / 2017$ & 1. & & & \multicolumn{2}{|c|}{$\sqrt{\checkmark}$ Custom Checkbox 1} \\
\hline 30 & $12 / 03 / 2017$ & 1. & & & \multirow{3}{*}{\multicolumn{2}{|c|}{$\begin{array}{l}\sqrt{ } \text { Custom Checkbox } 2 \\
\text { Custom Checkbox } 3 \\
\sqrt{\checkmark} \text { Reset on Connect }\end{array}$}} \\
\hline 31 & $12 / 03 / 2017$ & 1. & & & & \\
\hline 32 & $12 / 03 / 2017$ & 1. & Port: & 3 & & \\
\hline 33 & $12 / 03 / 2017$ & \multirow{2}{*}{\multicolumn{2}{|c|}{ Baud: }} & & \multirow{2}{*}{ Reset Timer } & \\
\hline 34 & $12 / 03 / 2017$ & & & & \multirow{2}{*}{\multicolumn{2}{|c|}{ Clear Columns }} \\
\hline 35 & $12 / 03 / 2017$ & 1. & \multicolumn{2}{|c|}{ Connect } & & \\
\hline 36 & $12 / 03 / 2017$ & 1. & \multirow{2}{*}{\multicolumn{2}{|c|}{ Pause logging }} & \multirow{2}{*}{\multicolumn{2}{|c|}{ Display direct debug $=>$}} \\
\hline 37 & $12 / 03 / 2017$ & 1. & & & & \\
\hline 38 & $12 / 03 / 2017$ & 1. & \multirow{2}{*}{\multicolumn{2}{|c|}{$\begin{array}{l}\text { Sheet name to post to: } \\
\text { (reload after renaming) }\end{array}$}} & & \\
\hline 39 & $12 / 03 / 2017$ & 1. & & & Further sheet $=$ & Less \\
\hline 40 & $12 / 03 / 2017$ & 1. & \multirow{2}{*}{\multicolumn{4}{|c|}{ Controller Messages: }} \\
\hline 41 & $12 / 03 / 2017$ & 1. & & & & \\
\hline 42 & $12 / 03 / 2017$ & 1. & \multicolumn{4}{|c|}{ PLX-DAQ Status } \\
\hline 43 & $12 / 03 / 2017$ & 1. & \multirow{2}{*}{\multicolumn{4}{|c|}{$\begin{array}{l}\text { Do not move this window around while logging ! } \\
\text { That might crash Excel! }\end{array}$}} \\
\hline 44 & $12 / 0.3 / 2017$ & 1 & & & & \\
\hline
\end{tabular}

Fig. 12. Graphical User of PLX-DAQ-v2.10 
Also, we have tested the performance of system in related to the system uses energy from PV. The performance of the PV to supply energy and to powerized the proposed system is shown in fig. 11.

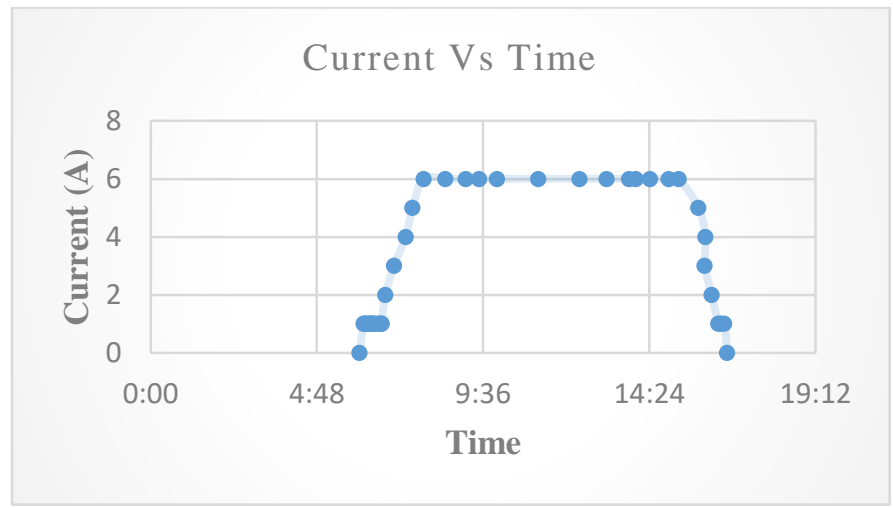

Fig. 11. Graphic Current Vs Time

Based on the experiment, we know that PV can provide a current at 06.09 O'clock until 16.34 O'clock. The power provide by PV depend on light intensity from the sun. From the graph above, PV can provide maximum power start from 07.53 O'clock till 15.15 O'clock, that was produced current at 6 Ampere. All current information measure by MPPT Solar Charge Controller (T40). This T40 has regulation for PV off, Load off, and Load On. PV off is a regulation to discharge the battery charging while voltage on the battery reach the value of PV off. Load off is to discharge used of the load, so the system will focus on charging battery. The last one is Load On that allow the system to give power to the load. At this experiment, PV off set on 12.6 Volt, Load off set on 10.5 Volt, and Load on set on 12 Volt.

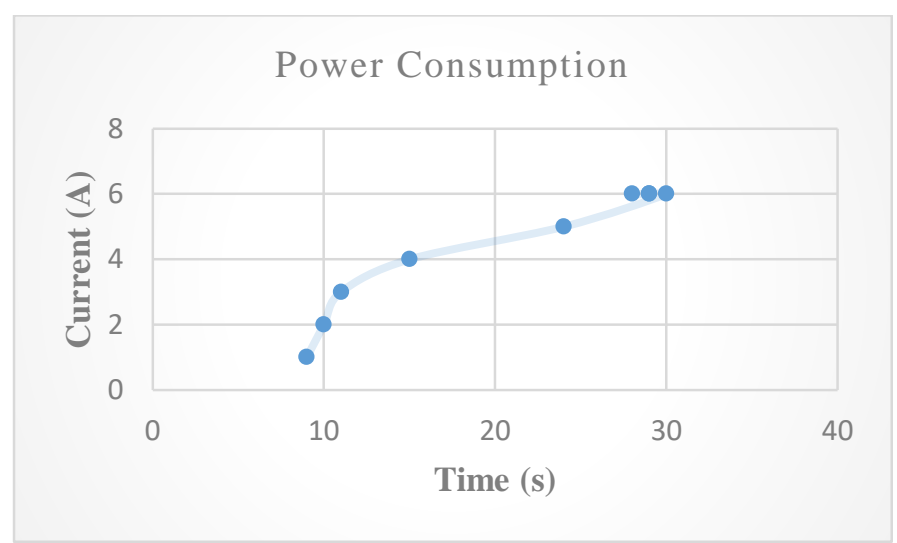

Fig. 12. Graphic Current Vs Time

The graph in fig. 12 give information about how long battery use for 2 motor Bilge pump $1100 \mathrm{GPH}$. This two motor spend of power 12 Volt 16 Ampere to turn the motor on when it use as direct operation, in this case not used arduino and others electronic to connect to the motor. Whereas, both of two motor only needed 12 Volt 7 Ampere while use all system. This graph based on direct opeartion, not use arduino and others. From the graph, the greater input of current, allow to take more time of used energy of the battery until it turn into charging mode. While charging mode, connection to the load is discharge.

The time to charge battery from PV until the battery capacity full is shown at fig. 13. The graph mean that the greater input current, so the time to charge the battery will be quickly. On this experiment, at maximum current $6 \mathrm{~A}$, it take 52 second.

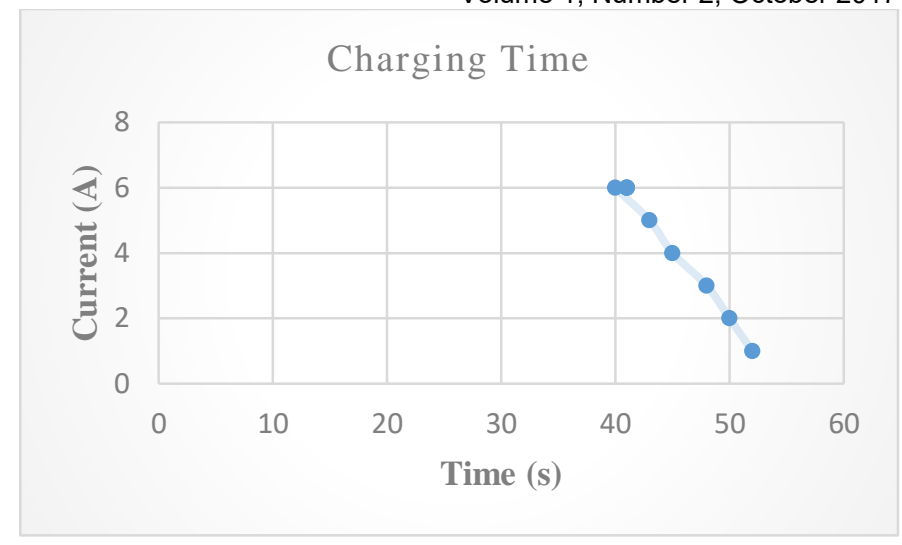

Fig. 13. Charging Time

The experiment to tested the performance is used $3 \mathrm{PV}$ with parallel configuration, so total current is sum of current from each PV. While testing, PV is positioned such as positioned at the Repeater Station, that was approach 0 degree or in flat place. The expectation with this positioned is it reflect the real system such as the experiment when operated the robot. The experiment do at the roofop of Microcontroller Laboratory (A206) Sepuluh Nopember Institute of Technology (ITS), and the documentation while do the experiment is shown in fig 14. Each PV module have capacity $100 \mathrm{Wp}$ (Watt Peak) and the eficiency is too small, so total power as input only 13.8 Volt 6 Ampere at maximum power or in the amount of 82.8 Watt. So, that was still smaller than the power needed when direct operation, in the amount of 192 Watt (or 12 Volt 16 Ampere). Whereas, when the Repeater Station is operated with all system, its only needed 12 Volt 7 Ampere, so the power from PV can supply power needed of the systems while it use all systems.
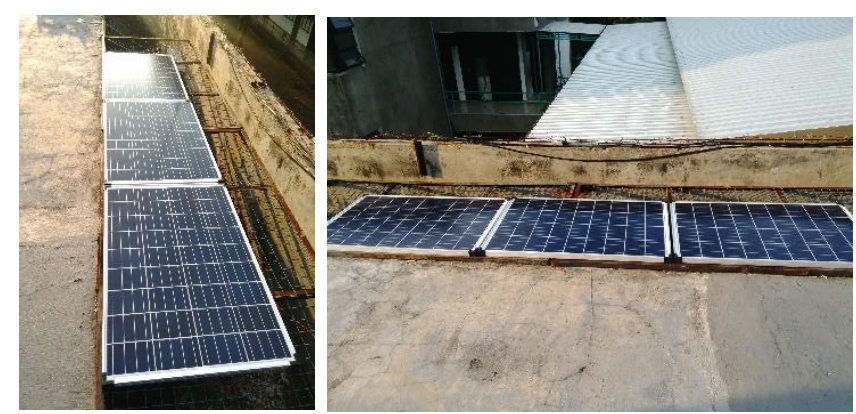

Fig. 14. Tested The Performance of Supply from PV

\section{CONCLUSION}

Repeater Station is a new innovation to assist the communication between control station with ROV underwater robot in wireless way without any attenuation at the signal transmission because the signal through air-water boundary. Power management for this Repeater Station and ROV is supplied by PV on the Repeater Station. So that, the ROV can controlled directly from far away with wireless way and can operated for a long time.

\section{REFERENCES}

[1] PPPGL, "Morfologi Dasar Laut Indonesia," 2016. [Online]. Available: www.mgi.esdm.go.id/content/morfologi-dasar-laut-indonesia. [Accessed 26 March 2017].

[2] F. Irawan and A. Yulianto, "Perancangn Prototype Robot Observasi Bawah Air dan Kontrol Hovering Menggunakan Metode PID Control," Jurnal Sains dan Informatika, vol. I, no. 1, pp. 63-70, 2015.

[3] Indomiliter, "ROV Si Robot Penyelam Laut Dalam," 2015. [Online]. Available: http://www.indomiliter.com/rov-si-robot-penyelam-lautdalam/. [Accessed 6 April 2017]. 
[4] S. Sivcev, J. A. D. Coleman, G. Dooly, E. Omerdic and D. Toal, "Closing The Gap between Industrial Robots and Underwater Manipulators," Washington, 2015.

[5] J. Singh, D. Gandhi, M. Sanghani, P. Robi and S. Dwivedy, "Design and Development of Underwater Robot," in International Conference on Robotics, Automation, Control and Embedded Systems - RACE 2015, Chennai, 2015.

[6] M. S. Gitakarma, K. U. Ariawan and N. A. Wigraha, "Alat Bantu Survey Bawah Air Menggunakan AMOBA, Robot Berbasis ROV," Jurnal Sains dan Teknologi, vol. III, no. 2, pp. 392-409, 2014.

[7] Assodivers, "Venom 3k-200," 2013. [Online]. Available: http://www.assodivers.gr/en/equipment/rovs/venom/. [Accessed 8 April 2017].

[8] F. T. Putri, M. Ariyanto, Ismoyo, M. Arozi, W. Caesarendra and M. R. Ibrahim, "Development of Unmanned Aerial Vehicle (UAV) Ornithopter with Wireless Radio Control," Semarang, 2016.

[9] M. A. B. Yusof and S. Kabir, "Underwater Communication Systems: A Review," Progress In Electromagnetics Research Symposium Proceedings, Marrakesh, Morocco, pp. 803-807, 2011.

[10] E. H. Henriksen, I. Schjolberg and T. B. Gjersvik, "UW MORSE: The UnderWater Modular Open Robot Simulation Engine," Autonomous Underwater Vehicles (AUV) 2016, vol. I, no. 16, pp. 261-267, 2016.

[11] B. Anto, E. Hamdani and R. Abdullah, "Portable Battery Charger Berbasis Sel Surya," Jurnal Rekayasa Elektrika, vol. XI, no. 1, pp. 1924, 2014. 